\title{
The Interplay of Economic, Social and Political Fragmentation
}

by Steven J. Bosworth and Dennis J. Snower

Discussion Paper No. 2019-17

Department of Economics University of Reading Whiteknights

Reading

RG6 6AA

United Kingdom

www.reading.ac.uk 


\title{
The Interplay of Economic, Social and Political Fragmentation
}

\author{
Steven J. Bosworth and Dennis J. Snower
}

This version: 27 August 2019

\begin{abstract}
We develop a model of the social fragmentation along communitarian vs. individualistic values. The endogenous adoption of social values hinges on whether people choose to derive more utility from comparisons with others (materialistic but universalist values) or derive relatively more utility from membership of a group with its distinguishing characteristics (communitarian but exclusive values). Those more well-off, socioeconomically, gravitate towards individualism while those of lower status gravitate towards communitarianism. Crucially, those at the lower end of the middle classes are predicted to align more and more with communitarian values when the status advantage of those at the top increases, holding their own income constant (i.e. rising socioeconomic inequality). Conversely, those at the higher end of the middle classes are predicted to align more and more with individualist values, polarising society. These shifts also increase size of the political constituency for enacting protectionist policies, which act as a stabilising force against socioeconomic polarisation. The model therefore predicts political realignments from the incidence of income growth and the importance of status-oriented (conspicuous) consumption.
\end{abstract}

\section{Introduction}

This paper examines the interactions between economic fragmentation (in terms of income inequality), social fragmentation (in terms of social identities) and political fragmentation (in terms of support for economic policies). Our analysis provides a framework for thinking consistently about these issues. In particular, we explore how inequalities arising from skill-biased growth can generate disparities in social identities and how these social disparities can generate political divisions concerning economic policies with regard to market openness. Depending on whether the economic policies enacted reduce or widen socioeconomic inequalities, there is a further feedback into economic fragmentation which may dampen or reinforce structural change respectively.

The motivation for our analysis is to shed light on the economic causes and consequences of the liberal-conservative divide in values underlying various sociodemographic divides (e.g. urban vs. rural). Our analysis shows how the widening income gap between skilled and unskilled people can lead to social fragmentation ${ }^{1}$ manifested through disparities in identity choice, with the skilled people adopting relatively individualistic identities and the unskilled preferring relatively communitarian identities. ${ }^{2} \mathrm{We}$ interpret this division between individualistic and communitarian identities in moral terms. In our

\footnotetext{
${ }^{1}$ See Rodrik (2014) on culture versus incentives. Our analysis portrays a reflexive relation between the two.

${ }^{2}$ G. Akerlof and Kranton (2000) pioneer identity economics. We follow R. Akerlof (2017) in modelling identity determination as a utility maximisation problem over values given fixed abilities of heterogeneous agents.
} 
analysis, individualistic moral values are centred on fairness (rewarding individuals in accordance with their desert) and care (supporting them in accordance with their need), whereas communitarian moral values include loyalty to one's social group alongside other values that promote social cohesion (such as respect for authority, tradition and sanctity, as well as conformity with social norms). This division between individualists and communitarians is shown to generate support for disparate economic policies, with the individualists favouring "open" policies (namely, policies promoting free trade and materialistic pursuits), while the communitarians favour "closed" policies (namely, policies promoting protectionism and community building).

In short, we interpret the liberal-conservative divide in terms of distinct moral systems. The relation between moral systems and social structure has been studied by anthropologists and cultural psychologists, who emphasize the distinction between individualism and collectivism (stressing the independence and interdependence of individuals, respectively). ${ }^{3}$ This distinction is closely related to Tönnies's contrast between "Gesellschaft" (civil society) and "Gemeinschaft" (community). In the former, people are free to make their own choices as long as they don't harm or cheat one another; in the latter, people's actions - in the context of small communities connected through longstanding propinquity and cultural affinity - are monitored, judged and regulated by others. Kesebir and Haidt (2010) have shown empirically that individualistic social settings (such as those in large Western cities) draw predominantly on the moral concerns of care and fairness, while collectivistic settings (such as those in small, traditional villages) draw on a wider range of moral sources, including loyalty, respect for authority and sanctity. In this sense, they the liberals with individualistic identities draw on narrower moral foundations than the conservatives with communitarian identities. We will show how skill-biased growth induces the individualists to withdraw some of their support from social communities in order to focus more on materialistic status seeking. In this sense, skill-biased growth leads to a narrowing of a society's moral foundations (as described further in Section 2) which has a feedback effect on technology (as interpreted in a political economy sense, see Section 5).

The liberal-conservative divide manifests itself in many forms: Democrats versus Republicans in the United States, Remainers versus Leavers in the Brexit referendum, the cosmopolitan elites versus the populist nationalists, the secular materialists versus the religious traditionalists, and so on. As noted, we interpret this conflict as one between individualism and communitarianism as drivers of economic decisions. Our conception of liberalism and conservatism reflects this divide: "Liberals" advocate universalist ideologies in support of individual economic and political freedoms (human rights, civil liberties, protection of minorities, checks and balances), the free movement of goods and services, lobar, capital and ideas across national borders), and free-market economic activity shaped by equity- and efficiencypromoting policies to deal with market failures, typically conducted by technocratic experts. By contrast,

\footnotetext{
${ }^{3}$ For example, Shweder and Bourne (1984), Markus and Kitayama (1991) and Triandis (1995).
} 
"conservatives" advocate ideologies in support of traditional social structures, including the political interests of a nation (e.g. "America first") or a religion (e.g. Islamism), in the name of "the people" (citizens of the nation or members of a religious community) as opposed to "the elite." In recent years, this liberal-conservative divide has played a major role in politics (such as in the Brexit vote and the election of Donald Trump) and economic policy (such as protectionism and migration restrictions). It is an important economic phenomenon, for which we will explore its economic causes and consequences.

In this context, our analysis provides an explanation for why the unskilled voters often support economic policies (such as protectionism) that may be expected to make these voters economically worse off. Intuitively, there are two domains of human need: the individualistic domain, where welfare depends on individual payoffs, such as the amount of goods and services consumed, and the social domain, where welfare depends on affiliation to social groups, expressed through contributions to a common cause. Conventional economic theory focuses on the individualistic domain, evaluating economic outcomes in terms of the consumption opportunities they generate. While liberal politicians have focused on the individualistic material needs of individuals, conservative politicians have been relatively more sensitive to people's need for communal affiliation. By focusing on the individualistic domain, conventional economic theory has thus provided more support for the work of liberal politicians than conservative ones. From this individualistic perspective, it is puzzling why unskilled voters should support protectionist policies. But once the social domain is taken into account, their voting behaviour may be understood as an expression of the importance their attribute to the social domain relative to the individualistic one. That is, there is very little evidence to suggest there are economic reasons why Northern England would favour Brexit, ${ }^{4}$ or why Appalachia would benefit from a U.S. trade war with China. Our theory steps in and provides a parsimonious link between the relative economic deprivation of such sub-national groups and their support for nativist economic policies.

An analysis of the liberal-conservative divide requires the recognition that people are not merely maximizers of their individual utilities, but are also social creatures pursuing social relationships within social groups. Sociality has been an integral part of human psychology and behaviour, though ignored in the individualistic decision making of conventional microeconomic theory. Throughout the evolutionary process, human beings have struggled with the "Me-Us problem," balancing the interests of the individual against those of his or her social group (see Joshua Green's Moral Tribes). The success of the human species is due in large part to our ability to cooperation with one another beyond the bounds of kinship, in part through the creation of moral intuitions and precepts that honour the demands of "Us" along with moral narratives that widen the domain of "Us" beyond our tribe to encompass nations, empires and civilizations. Accordingly, this paper presents an economic model that is appropriately extended beyond the individualistic decision making to include affiliative relations within social groups.

\footnotetext{
${ }^{4}$ Though support for Brexit was significantly associated with local economic grievances (Arnorsson and Zoega, 2018). See Fetzer (2018) on the link between austerity and the Brexit vote.
} 
The liberal argument that the losers from structural economic change can be compensated if the overall economy grows may not hold because more than merely money is required to balance the ledger. Our analysis suggests that under the influence of skill-biased growth (generated by globalisation and technological advance), the relatively unskilled individuals have been "left behind" in an economic sense and two social senses. Economically, the gap between their purchasing power and that of the skilled individuals has risen. Socially, they have lost positional status (associated with rising envy and declining social recognition) and they have experienced the unravelling of their communities (associated with rising insecurity and declining self-esteem). Our analysis indicates that these are drawn to conservative politicians who promise the restoration of their communities, while becoming disaffected from liberal politicians who attach more weight to absolute purchasing power than to social solidarity.

Many commentators have noted that the winners from the globalisation and innovation process tend to favour cosmopolitan social and political goals, such as international status comparisons and free international trade. This is scarcely surprising, since the process of globalisation and innovation relies heavily on the free movement of lobar, capital and ideas (see Baldwin, 2016). The losers from the globalisation process, by contrast, attach relatively more weight to communal goals, which are more inward-looking than the cosmopolitan goals of the winners. When the inward-looking, disadvantaged group gains the political upper hand, governments may embrace pursue protectionism, even if this reduces this group's living standards.

Our analysis is based on the following assumptions. First, people can pursue both individualistic and social objectives. We will view the wellbeing generated in pursuit of their social objectives as public goods that arise from their social affiliations within groups. Second, people's individualistic and social objectives need not be mutually exclusive. They can, if they wish, pursue both objectives alongside one another. Their ideologies - liberal versus conservative - will be distinguished in terms of the mix of objectives that they pursue. Third, the weights that they attach to these objectives is associated with their values-based identities. We interpret identities as social roles within groups. Different identities are associated with different underlying moral values. Finally, per R. Akerlof (2017), we assume that these identities are not exogenously given, but that people gravitate towards those identities which promote their wellbeing. We model this as a utility maximization problem, though of course this choice may not be deliberate.

Our model distinguishes between two identities: an individualistic and a communitarian identity. The individualistic identity is based on individualistic and positional values, linked to distinct economic objectives (individualistic consumption of marketable commodities, as well as positional competition in terms of these commodities). These values are centred on personal autonomy (including the values of personal agency, personal achievement and status) alongside respect for the intrinsic worth of all other other individuals. By contrast, the communitarian identity is driven by the values of affiliation to social 
groups, including values of loyalty to one's social group, respect for authority, as well as sensitivity to issues of sanctity and purity (around which social groups often cohere). These values induce individuals to contribute to a common cause, whose benefits are shared by all members sharing communitarian values. These benefits may include economic goods (such as public education and health services) and cultural goods (such as support for national, ethnic or religious traditions). ${ }^{5}$ These goods are club goods, since they are excludable (i.e. their benefits are not available to those who do not choose communitarian values) and non-rival (i.e. since one individual's consumption does not interfere with another's consumption of the goods).

These two value systems are consistent with those identified by various social and moral psychologists and moral anthropologists. In particular, Shweder and co-authors have proposed that different cultures provide two distinct answers to the question of how the needs of individuals and groups are to be weighted: the sociocentric approach subordinates the needs of individuals to those of their social groups, whereas the egocentric approach gives priority to the needs of individuals (e.g. Shweder and Borne, 1984). The sociocentric approach was dominant in most ancient cultures and the individualistic approach was central in the Enlightenment. In Shweder's analysis, the sociocentric approach follows the values of community and divinity, while the egocentric approach adheres to the value of autonomy. In Schwartz's investigation of moral universals, individualistic values cover those favouring universalism (appreciation, tolerance and wish to protect all people), independent thought and action, openness to novelty and change, status and control, achievement, and gratification of the senses; whereas sociality-based values cover acceptance and commitment to traditions, conformity and self-control in line with social expectations, and desire for harmonious, stable and safe social relationships (e.g. Schwartz, 1994). In Haidt's moral foundation theory, the individualistic values involve care and fairness, and the sociality-based values involve loyalty, authority and sanctity (e.g. Haidt, 2012).

In conventional neoclassical economic analysis, individualistic and materialistic values are reduced to a Benthamite core, in which each individual's self-interest is reduced to the maximization of individual utility from consumption and social welfare is the sum of all individual utilities in a society. As an individual's marginal utility is assumed to decline with consumption, the maximization of social welfare involves distributing consumption "fairly," in the sense of equalizing consumption across individuals. Sociality-based values are ignored in this analysis.

The paper is organized as follows. Section 2 discusses the gradual narrowing of our moral foundations. Section 3 models the economic activities of the individualists and communitarians and describes the principles of identity choice between these groups. Section 4 investigates the influence of skill-biased technological change on this identity determination, corresponding to a choice of moral values. Section 5 explores the implications for government policy, showing how skill-biased technological change may give

\footnotetext{
${ }^{5}$ This distinction is analogous to that between individualistic and prosocial value orientations (e.g. van Lange et al., 1997).
} 
rise to a moral divide that generates protectionism. Section 6 concludes.

\section{The Narrowing of Our Moral Foundations}

Our analysis rests on an important observation, namely, that the rise of cosmopolitan, economic liberalism has led to a narrowing of our moral foundations. This observation has had little influence on economic analysis thus far.

In recent years moral psychologists, most prominently Haidt and co-authors, have argued that until the end of the Middle Ages, morality was predominantly about virtues, involving a broad range of moral concerns. It was only in the European Enlightenment that the focus shifted to logical moral principles, associated with a much narrower range of moral concerns. This evolution of morality has been termed "the Great Narrowing."

The virtues espoused largely prior to the Enlightenment emphasized admirable practices in welldefined contexts and were described in narratives (such as those contained in Homer's Illiad, the Torah, the Gospels, and Muhammad's Sunna) describing the actions and experiences of morally exemplary personalities. This virtue-based approach to morality remains important in tight-knit, traditional communities and religious groups (e.g. Bennet, 1993; Hunter, 1991). It has also received renewed attention in philosophy in recent decades (e.g. Chappell, 2006; Crisp, 1996; and MacIntyre, 1981).

By contrast, Enlightenment philosophers in Europe since the 18th century have sought to reassess ethics in terms of abstract, timeless, context-independent principles. The two dominant approaches were deontology (whereby actions are judged in accordance with their intrinsic rightness or wrongness) and consequentialism (whereby actions are judged by their consequences). These Enlightenment approaches viewed moral decisions as resulting from logical reasoning, rather than wholesome practices. Moral dilemmas were frequently posed in terms of issues in which deontological principles came into conflict with consequentialist ones. Pre-Enlightenment also involved abstract principles (such as "you shall not steal" and "love your neighbour as yourself"), though pre-Enlightenment moralists were not much concerned about possible conflicts among these principles.

The associated moral psychological concerns were focused predominantly on fairness (such as Kohlberg, 1969) and Rawls, 1971), who argued that reasoning about justice is central to moral development) and care (such as Gilligan, 1981; a major proponent of the "ethic of care."). These are the central concerns of Gesellschaft (enabling individuals to live peacefully and cooperatively in mobile societies), whereas the concerns of Gemeinschaft (characterized by "thick" interpersonal relationships) cover other communityrelated concerns, which Haidt identifies as loyalty, authority and sanctity.

It is in these senses, philosophical and psychological, that Enlightenment morality may be understood as the first Great Narrowing. A second Great Narrowing took place in personal empowerment and social 
solidarity in advanced Western countries, gaining pace over the past 150 years and particularly pronounced in the emergence of the postwar welfare state. This process is brilliantly described in Collier (2018). Until the end of the second World War, welfare services were primarily a decentralized outgrowth of community life. Throughout the Middle Ages, the church played a primary, though very patchy, role in Europe to provide support such as hospitals, orphanages, and alms for the poor. Jewish and Christian tithes and the Islamic zakat were extensions of individual charity to provide poor relief. With the passage of time, these welfare services were taken over by secular institutions. In 1530 German towns were given the legal obligation to care for their poor, in 1794 Prussian state became responsible to provide food and housing to those in need, and in 1810 a Prussian law gave masters the obligation to make medical services available to their servants. When the monasteries were dispossessed in England, the state assumed a minimal care of the poor. The Elizabethan "Old Poor Law" of 1601 made this governmental responsibility explicit, establishing categories of need and levying taxes for poor relief. Since these safety nets were paltry, cushioning people against economic adversity fell mainly on the communities to which they belonged: their family, friends, and fellow villagers.

With the Industrial Revolution, work ceased to be a way of life requiring the joint participation of extended families and communities, and became parcelled into marketable "jobs" associated with the fragmented tasks performed by machines capable of exploiting economies of scale in production. Once these changes in the organization of production led to complementary organizational changes, the fragmentation of job extended into management, product development and marketing. In short, the work generated by the Industrial Revolution was no longer a vocation that reinforced the existing social structures of support, but became a commodity to be bought and sold in the lobar market, with wages reflecting the forces of demand and supply. Thereby work lost its role as a social insurance policy, enabling people to contribute to a common social enterprise as long as they were able, in return for support when they were unable.

In the process, it became increasingly difficult, and often impossible, for the children and the aged to contribute to the support of their families. Consequently care of the young and the elderly became social problems. Since jobs under the new economic regime could be switched in the pursuit of material gain, the role of education became increasingly divorced from the workplace. With parents working in the factories rather than at home, and children no longer bound to pursue the occupations of their parents, the family ceased to be a natural source of education for the young. With the fragmentation of extended families and the break-up of traditional communities, education too became a social problem. The void left by the disappearance of traditional community support networks was filled, at least partially, by local associations in towns and cities. Nineteenth century Britain relied heavily on friendly societies for medical help and laws making employers liable for compensation in case of work-related injuries. These association functioned on the presumption of reciprocal social obligations: the obligation of the 
individual to contribute to the common weal linked to the obligation of the community to cushion the individual against major economic shocks. Gradually, however, the community support networks were eroded through the growing mobility of lobar and the rising interdependence of communities within national borders, making it difficult for these communities protect themselves against macroeconomic downturns. ${ }^{6}$

The welfare state gradually emerged, stepping into this void. In Prussia, Otto von Bismark introduced the first overall social insurance system in Germany. Sickness insurance, financed through taxes on employers and employees, became law in 1883; accident insurance was mandated in 1884; and pension rights, for workers over the age of 70, were established in 1889. Over the next decade and a half, somewhat similar developments occurred in Austria, Italy, the Netherlands, and Sweden. Various Latin American countries followed the German lead in the 1920s and 1930s.

In contrast to the German system of earnings-related benefits, the expansion of the welfare state in Britain emphasized the alleviation of poverty more than insurance against economic uncertainty. The friendly societies, accordingly, provided flat-rate benefits for illness. When pension rights were legalized in 1908, the payments were non-contributory and means-tested. Unemployment insurance and health insurance was introduced on a flat-rate basis as well in the National Insurance Act of 1911 . By the early 1930s, the United States was the only industrialized country without a state-run comprehensive social insurance system (with the significant exception of veterans' benefits). In response to the Great Depression of the 1930s, the federal government became a major provider of welfare services. The Social Security Act of 1935 provided some federal unemployment insurance, old-age insurance, disability insurance and assistance for mothers, widows, and dependent children.

The welfare state received another powerful impulse with the end of World War II. The British Beveridge Report of 1942 argued that the government should assume responsibility for full employment, national health, family allowances, and poverty assistance. In the United States, the Employment Act of 1946 made the federal government responsible "to use all practicable means... to promote maximum employment, production, and purchasing power... for the purpose of creating and maintaining, in a manner calculated to foster and promote free competitive enterprise and the general welfare, conditions under which there will be afforded useful employment opportunities, including self-employment, for those able, willing, and seeking to work." These and other initiatives in other countries worldwide greatly increased the central government's responsibilities to cushion people against adverse economic shocks, mitigate poverty, and conduct life-cycle and intergenerational transfers of income.

As the state's responsibilities grew, families, localities, religious associations, and other social group became marginalized in the task of supporting people in need. In the process, the connections between

\footnotetext{
${ }^{6}$ These economic and cultural shifts often fed on and reinforced each other, as in the case of Jewish emancipation in nineteenth-century Europe. Carvalho and Koyama (2016) explain how new economic opportunities polarised communities, some of whom integrated into Gentile society while others adopted an increasingly strict religious orientation.
} 
the financial supporters, providers and recipients of welfare services became progressively weaker. The the earlier sense of reciprocal obligation between individuals and their communities was replaced by national and regional systems of taxes and transfers, mediated by bureaucrats in government agencies. It was inevitable that the citizens would come to feel progressively disempowered and socially alienated by this paternalist system of redistribution and macroeconomic management. This second Great Narrowing reinforced the contraction of the moral concerns underlying the provision of welfare services from those of Gemeinschaft (characterized by reciprocal social obligations, reinforced by loyalty, authority and sanctity, as well as the ethics of justice and care) to those of Gesellschaft (focused exclusively on care and justice).

The third Great Narrowing took place within the discipline of economics and extended from there to other domains, public and private. ${ }^{7}$ Under the influence of Enlightenment philosophers, particularly Jeremy Bentham and John Stuart Mill, the economics discipline became dominated by utilitarianism, a special branch of consequentialism concerned with the "utility" generated by economic activities. Bentham conceived "utils" as a measure of happiness and advocated that the morality of actions should be judged in terms of whether they promote "the greatest happiness of the greatest number." Under the influence of the marginalists, utility came to be conceived as whatever people must be maximizing in order to make their economic decisions. Furthermore, the consumption of goods and services came to be understood as the only source of utility. Beyond that, economics came to be dominated by methodological individualism and individuals were conceived as selfish, materialistic creatures, solely concerned about the utility flowing to themselves personally from their consumption activities. The result was Homo Economicus, a creature satisfying the clinical diagnostic criteria of a psychopath.

In this context, the moral concern of "care" shrivelled to providing needy citizens with consumption and the concern of "justice" shrivelled to distributional fairness, interpreted as equalizing consumption across citizens. The socially desirable equalization of consumption through taxes and transfers was limited by efficiency considerations. The "equity-efficiency tradeoff" described the degree to which the size of the national pie shrank when the pie was redistributed. From the traditional perspective of economics, society consists of households, firms and the government. Households and firms are assumed to be utterly amoral, maximizing their own utility and profits, respectively. The only moral actor left was the government, whose moral choices were reduced to choosing a point on the economy's equity-efficiency tradeoff. As economic modelling came to dominate the state's economic decisions and as more and more aspects of life became commercialized (e.g. Sandel, 2012), management of the economy became increasingly technocratic, as government bureaucrats became the main implementers of economic policies balancing equity and efficiency objectives focused on consumption opportunities. This constituted the most radical narrowing of the moral space in the transition from Gemeinschaft to Gesellschaft.

\footnotetext{
${ }^{7}$ This narrowing is also described in Collier (2018).
} 


\section{$3 \quad$ Values and Identities}

We assume that people can have one of three identities: an "individualistic" $(I)$ identity in which utility derives only from individualistic pursuits, a "communitarian" $(C)$ identity aligned totally with sociocentric values and in which utility is derived solely from communitarian pursuits, or a "multi-affiliated" $(M)$ identity which adopts both sociocentric and egocentric values and in which utility is derived from both communitarian and individualistic pursuits. In this context, we aim to capture Haidt's empirical observation that people can be sensitive to a broader range of values than individualism, to varying degrees. In this context, when people switch from a multi-affiliated identity to an individualistic one, a moral narrowing occurs. A similar narrowing of values happens when people switch from a multi-affiliated to a purely communitarian identity: people cease to become competing individuals and identify themselves with a broader community such as the nation.

Let $U_{i}^{I}$ represent the utility from an individualistic identity (pursuing egocentric values), $U_{i}^{C}$ represent the utility from a communitarian identity (pursuing sociocentric values), and $U_{i}^{M}$ represent the utility from a "multi-affiliated identity" (pursuing both sociocentric and egocentric values). Each individual $i$ adopts the utility-maximizing identity:

$$
U_{i}=\max \left\{U_{i}^{I}, U_{i}^{C}, U_{i}^{M}\right\}
$$

We now proceed to specify each of these utilities. ${ }^{8}$

\subsection{Individualistic Identity}

A person with an individualistic identity can derive utility from self-interested and status-oriented pursuits, both of which are expressions of egocentric values. The utility from an individualistic identity is

$$
U_{i}^{I} \equiv U_{i}^{s}+x_{i}
$$

where $x_{i}$ represents individual $i$ 's self-interested consumption of private goods (excludable and rival), $U_{i}^{s}$ is the individual's utility from status-seeking activities (described below). The relative weight of selfinterested and status-seeking pursuits in the utility function may be adjusted through the parameters $\pi$ and $\varepsilon$ of the status-seeking utility function below. ${ }^{9}$

Each individual $i$ produces $x_{i}$ market goods, whose production function is $x_{i}=\beta_{j}\left(1+a_{i}\right)$, where $a_{i}$ is the individual's skill or ability (higher $a_{i}$ stands for higher ability) and $\beta_{j} \in\left\{\beta_{u}, \beta_{s}\right\}>0$ is a

\footnotetext{
${ }^{8}$ This model is superficially similar to that used in Snower and Bosworth (2016), though the purposes of the two models are obviously different.

${ }^{9}$ Specifically, the relative magnitudes of $\pi$ and $\varepsilon$ represent the relative strengths of the pride and envy effects, respectively; the absolute magnitudes of both $\pi$ and $\varepsilon$ reflect the weighting of status-seeking versus self-interested pursuits in the utility function.
} 
"productivity parameter" that we will use to capture the return to market activities. $\beta_{j}$ may change in response to globalisation, automation, public policy, or other structural economic shifts. When $\beta_{u} \neq \beta_{s}$ the returns to market activities may differ for people of different socioeconomic status. Skill-biased growth can in this way be represented by a rise in $\beta_{s}$ while $\beta_{u}$ remains constant. Ability is uniformly distributed over the range $[0,1]$. We assume that in the lower segment of the ability distribution $\left(a_{i} \in\left[0, a_{s}\right]\right)$, the productivity parameter is $\beta_{j}=\beta_{u}$ (where subscript $u$ stands for "unskilled", whereas for the upper segment of the ability distribution $\left(a_{i} \in\left(a_{s}, 1\right]\right)$ the productivity parameter is $\beta_{j}=\beta_{s}$, where $\beta_{u} \leq \beta_{s}$.

Each person $i$ competes with a random member of society. The resulting utility from positional competition with another person $j$ is

$$
U_{i, j}^{s} \equiv \pi \max \left(x_{i}-x_{j}, 0\right)-\varepsilon \max \left(x_{j}-x_{i}, 0\right)
$$

where $\pi>0$ is a pride parameter and $\varepsilon>\pi$ is an envy parameter. Boyce et al. (2010) suggest that $\varepsilon>\pi$, which we will assume. Status seeking is often personalised, focused on individuals who have one's attention at a particular time. We adopt however the simplification that attention is proportionally distributed across society in order to derive qualitative results as parsimoniously as possible. The individual's expected utility from competing with a random outsider is

$$
a_{i} U_{i}^{\underline{s}}+\left(1-a_{i}\right) U_{i}^{\bar{s}}
$$

where here $a_{i}$ represents the probability of encountering an inferior-ability outsider and $U_{i}^{s}$ is $i$ 's pridedriven utility from this encounter, whereas $\left(1-a_{i}\right)$ is the probability of encountering a superior-ability outsider and $U_{i}^{\bar{s}}$ is $i$ 's envy-driven utility from that encounter. Denote by

$$
U_{i}^{s} \equiv E\left(U_{i, j}^{s}\right)=a_{i} U_{i}^{s}+\left(1-a_{i}\right) U_{i}^{\bar{s}}
$$

$i$ 's overall expected utility from status seeking. Taking the expectation of $U_{i, j}^{s}$ over the appropriate intervals yields

$$
\begin{aligned}
U_{i}^{s} & =a_{i} \pi \int_{0}^{a_{i}}\left(x_{i}-x_{j}\right) d a_{j}-\left(1-a_{i}\right) \varepsilon \int_{a_{i}}^{1}\left(x_{j}-x_{i}\right) d a_{j} \\
& =\left\{\begin{array}{ll}
\frac{1}{2}\left(a_{s}\left(2+a_{s}\right)\left(\beta_{s}-\beta_{u}\right) \varepsilon-\left(3 \beta_{s}-2\left(1+a_{i}\right) \beta_{u}\right) \varepsilon-a_{i}^{2} \beta_{u}(\varepsilon-\pi)\right) & a_{i} \leq a_{s} \\
\frac{1}{2}\left(\beta_{s}\left(a_{i}^{2} \pi-\left(1-a_{i}\right)^{2} \varepsilon\right)+a_{s}\left(2+a_{s}\right)\left(\beta_{s}-\beta_{u}\right) \pi\right) & a_{i}>a_{s}
\end{array} .\right.
\end{aligned}
$$

This equation shows how utility from positional competition depends on an individual's ability level. 


\subsection{Communitarian Identity}

We assume that a person with a communitarian identity derives utility from communitarian pursuits that express sociocentric values, as well as self-interested pursuits, since everyone is instinctually inclined to satisfy self-interest to some degree. The utility from a communitarian identity, pursuing sociocentric values, is

$$
U_{i}^{C} \equiv U_{i}^{q}+x_{i}
$$

where $U_{i}^{q}$ represents the benefit from communitarian activities, which yield non-rival benefits to the participants. The relative weights of the communitarian and self-interested pursuits in the communitarian utility function can be adjusted through the parameter $\alpha$ in equation (7) below.

Since the benefits are available only to individuals pursuing sociocentric values and since one individual's enjoyment of these benefits does not go at the expense of another individual's enjoyment, the outputs of the communitarian activities are club goods.

Since the benefits from these goods are shared by all individuals pursuing sociocentric values, we specify the utility derived from these club goods simply as

$$
U_{i}^{q}=\alpha
$$

where $\alpha$ is a constant.

\subsection{Multi-affiliated Identity}

The utility from a multi-affiliated identity, pursuing both egocentric and sociocentric values, is

$$
U_{i}^{M} \equiv \frac{\phi}{\sigma^{C}} U_{i}^{q}+\frac{1-\phi}{\sigma^{I}} U_{i}^{s}+x_{i}
$$

where $\phi$ is the "salience parameter" $(0<\phi<1)$, measuring the degree to which the communitarian utility is salient for someone with a multi-affiliated identity, and $\sigma^{C}$ and $\sigma^{I}$ are the weights of the communitarian and individualistic goals for the multi-affiliated identity, respectively.

In order to avoid trivial results, we assume that $\sigma^{I}, \sigma^{C}<1$ with $\sigma^{C}>\phi$ and $\sigma^{I}>1-\phi$. The parameter $\sigma$ captures the degree of imperfect substitutability between communitarian activities and status-seeking activities.

The human needs for material prosperity and sociality are not seen by psychologists and neuroscientists substitutable for one another (see Panksepp, 1998). There is a wide literature in the psychology of wellbeing showing that an excess of materialism is detrimental to happiness (Ryan and Dziurawiec, 2001; Kasser, 2002; Roberts and Clement, 2007). These effects may be nonlinear however, and some materialism is happiness-promoting (Hudders and Pandelaere, 2012; Pieters, 2013). 


\subsection{Identity determination}

Expressing the three utility functions in terms of ability, we find

$$
\begin{aligned}
U_{i}^{I} & = \begin{cases}\frac{1}{2}\left(a_{s}\left(2+a_{s}\right)\left(\beta_{s}-\beta_{u}\right) \varepsilon-\left(3 \beta_{s}-2\left(1+a_{i}\right) \beta_{u}\right) \varepsilon-a_{i}^{2} \beta_{u}(\varepsilon-\pi)\right)+x_{i} & a_{i} \leq a_{s} \\
\frac{1}{2}\left(\beta_{s}\left(a_{i}^{2} \pi-\left(1-a_{i}\right)^{2} \varepsilon\right)+a_{s}\left(2+a_{s}\right)\left(\beta_{s}-\beta_{u}\right) \pi\right)+x_{i} & a_{i}>a_{s}\end{cases} \\
U_{i}^{M} & = \begin{cases}\frac{1-\phi}{2 \sigma^{I}}\left(a_{s}\left(2+a_{s}\right)\left(\beta_{s}-\beta_{u}\right) \varepsilon-\left(3 \beta_{s}-2\left(1+a_{i}\right) \beta_{u}\right) \varepsilon-a_{i}^{2} \beta_{u}(\varepsilon-\pi)\right)+\frac{\phi \alpha}{\sigma^{C}}+x_{i} & a_{i} \leq a_{s} \\
\frac{1-\phi}{2 \sigma^{I}}\left(\beta_{s}\left(a_{i}^{2} \pi-\left(1-a_{i}\right)^{2} \varepsilon\right)+a_{s}\left(2+a_{s}\right)\left(\beta_{s}-\beta_{u}\right) \pi\right)+\frac{\phi \alpha}{\sigma^{C}}+x_{i} & a_{i}>a_{s}\end{cases} \\
U_{i}^{C} & =\alpha+x_{i} .
\end{aligned}
$$

Note that both the individualistic and communitarian utility functions are each a special case of the multi-affiliated identity, with $\sigma=1, \phi=0$ and $\phi=1$ respectively. This means that individualists and communitarians gain utility from a narrower range of activities than those who are multi-affiliated, on account of their narrower range of values.

We now show that for reasonable restrictions on the parameters, those with the lowest ability prefer to adopt a purely communitarian identity, while those with the highest ability choose an individualistic identity. Those with abilities in the middle of the distribution will choose to adopt multi-affiliated identities. For $a_{i}=0$ (the lowest ability level), utility from the communitarian identity exceeds that from the multi-affiliated identity:

$$
U_{i}^{C}-U_{i}^{M}=\frac{1}{2 \sigma^{I}} \varepsilon(1-\phi)\left(\left(1-a_{s}\right)\left(3 \beta_{s}-2 \beta_{u}\right)+\left(1-a_{s}\right) a_{s} \beta_{s}+a_{s}^{2} \beta_{u}\right)+\frac{\alpha(1-\phi)}{\sigma^{C}}>0
$$

Furthermore, for $a_{i}=1$ (the highest ability level), the individualistic identity is preferred to a multiaffiliated identity:

$$
U_{i}^{I}-U_{i}^{M}=\frac{1}{2 \sigma^{I}}\left(\sigma^{I}-(1-\phi)\right) \pi\left(\beta_{s}+a_{s}\left(2+a_{s}\right)\left(\beta_{s}-\beta_{u}\right)\right)-\frac{\phi \alpha}{\sigma^{C}}>0
$$

provided that $\alpha$ is not too large. This means that the utility from communitarianism cannot exceed the utility from positional distinction for the richest person in society. In order to ensure that all three identities command some share of the population, we assume that the individual with $a_{i}=a_{s}$ prefers to adopt the multi-affiliated identity. ${ }^{10}$

Next, we show that the utility of adopting the individualistic identity over the multi-affiliated identity

\footnotetext{
${ }^{10}$ This entails $\frac{1}{2 \sigma^{I}}\left(\sigma^{I}-(1-\phi)\right)\left(\left(\left(1-a_{s}\right)^{2} \varepsilon-a_{s}^{2} \pi\right) \beta_{s}-\left(2 a_{s}+a_{s}^{2}\right)\left(\beta_{s}-\beta_{u}\right) \pi\right)+\frac{\phi \alpha}{\sigma^{C}}>0$ and $\frac{1}{2 \sigma^{I}}(1-\phi)$ $\left(a_{s}^{2} \beta_{u} \pi-\left(2\left(1-a_{s}\right)\left(\beta_{s}-\beta_{u}\right)+\left(1-a_{s}^{2}\right) \beta_{s}\right) \varepsilon\right)-\frac{\alpha\left(\sigma^{C}-\phi\right)}{\sigma^{C}}>0$.
} 
is continuously increasing in ability $a_{i}$ on the interval $\left[a_{s}, 1\right]$. Differentiating $U_{i}^{I}-U_{i}^{M}$ with respect to $a_{i}$,

$$
\frac{d\left(U_{i}^{I}-U_{i}^{M}\right)}{d a_{i}}=\frac{\beta_{s}}{\sigma^{I}}\left(\sigma^{I}-(1-\phi)\right)\left(\left(1-a_{i}\right) \varepsilon+a_{i} \pi\right)>0 .
$$

Thus the intermediate value theorem ensures that there is a cutoff ability $\widehat{a}^{I}$, at which the individual is indifferent between the two identities.

Furthermore, we show that the utility of adopting the middle class identity over the nationalistic identity is continuously increasing in ability $a_{i}$ on the interval $\left[0, a_{s}\right]$. Differentiating $U_{i}^{M}-U_{i}^{C}$ with respect to $a_{i}$,

$$
\frac{d\left(U_{i}^{M}-U_{i}^{C}\right)}{d a_{i}}=\frac{\beta_{u}}{\sigma^{I}}(1-\phi)\left(\left(1-a_{i}\right) \varepsilon+a_{i} \pi\right)>0
$$

Thus the intermediate value theorem ensures that there is a cutoff ability $\widehat{a}^{C}$, at which the individual is indifferent between the two identities. The cutoff abilities $\widehat{a}^{I}, \widehat{a}^{C}$ determine the relative sizes of the purely individualistic and communitarian populations and the degree of social integration in our model.

\section{The Influence of Skill-Biased Technological Change}

This section investigates the influence of economic fragmentation (e.g. skill-biased productivity improvements arising from technological progress or globalization) on the size of the three social groups. These are defined by changes in the location of the marginal individuals (with abilities $a_{i}=\widehat{a}^{I}$ and $\widehat{a}^{M}$ ), who determine the size of the individualistic and communitarian groups respectively. We represent skill-biased technological change by a rise in $\beta_{s}$, holding $\beta_{u}$ constant. In this context, the interesting case is one where the multi-affiliates straddle the divide in returns to ability (i.e. $\widehat{a}^{C}<a_{s}<\widehat{a}^{I}$ ), since these individuals may experience either benefiting from or being "left behind" by structural economic change.

For analytical simplicity, we focus on a baseline technology that is skill-unbiased: $\beta_{s}=\beta_{u}=\beta{ }^{11}$ Setting $\widehat{U}^{I}=\widehat{U}^{M}$ and solving for $a_{i}=\widehat{a}^{I}$, we obtain the size of those who adopt some degree of cummunitarianism (multi-affiliates included):

$$
\widehat{a}^{I}=\frac{\varepsilon}{\varepsilon-\pi}-\sqrt{\frac{\varepsilon \pi}{(\varepsilon-\pi)^{2}}-\frac{2 \phi \alpha \sigma^{I}}{\beta \sigma^{C}\left(\sigma^{I}-(1-\phi)\right)(\varepsilon-\pi)}}
$$

and setting $\widehat{U}^{M}=\widehat{U}^{C}$ and solving for $a_{i}=\widehat{a}^{C}$, we obtain the size of the purely communitarian group: ${ }^{12}$

$$
\widehat{a}^{C}=\frac{\varepsilon}{\varepsilon-\pi}-\sqrt{\frac{\varepsilon \pi}{(\varepsilon-\pi)^{2}}-\frac{2\left(\sigma^{C}-\phi\right) \alpha \sigma^{I}}{\beta \sigma^{C}(1-\phi)(\varepsilon-\pi)}} .
$$

The equilibrium distribution of values in society can be seen in Figure 1.

\footnotetext{
${ }^{11}$ This assumption is made to ease the analytical exposition. All results follow when the baseline technology is already skill-biased. Please refer to the appendix.

${ }^{12}$ It can be shown that our assumptions are sufficient for $\widehat{a}^{C}<\widehat{a}^{I}$.
} 


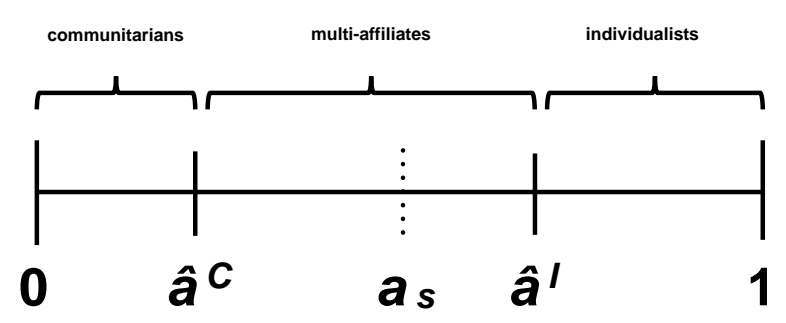

Figure 1: The distribution of values in society.

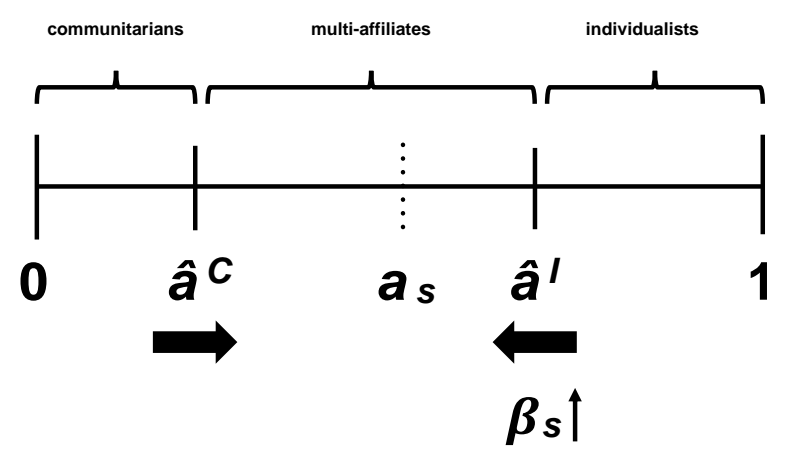

Figure 2: The effect of an increase in socioeconomic inequality.

The more numerous is the $M$ group, the more harmonious is the society, since this group embraces both value systems. However skill-biased technological change reduces the size of the $M$ group. As noted, we represent skill-biased technical change by a rise $\beta_{s}$, holding $\beta_{u}$ constant.

1 The size of the purely individualistic group rises with $\beta_{s}$, holding $\beta_{u}$ constant:

$$
\left.\frac{d \widehat{a}^{I}}{d \beta_{s}}\right|_{\beta_{s}=\beta_{u}=\beta}=-\frac{\left(\sigma^{I}-(1-\phi)\right)\left(2+a_{s}\right) a_{s} \beta \pi \sigma^{C}+2 \phi \alpha \sigma^{I}}{2 \beta \sqrt{\beta \sigma^{C}\left(\sigma^{I}-(1-\phi)\right)\left(\left(\sigma^{I}-(1-\phi)\right) \beta \varepsilon \pi \sigma^{C}-2 \alpha \phi \sigma^{I}(\varepsilon-\pi)\right)}}<0 .
$$

whereas those left behind increasingly favour pure communitarianism:

$$
\left.\frac{d \widehat{a}^{C}}{d \beta_{s}}\right|_{\beta_{s}=\beta_{u}=\beta}=\frac{\left(1-a_{s}\right)\left(3+a_{s}\right)(1-\phi) \sigma^{C} \varepsilon}{2 \sqrt{\beta \sigma^{C}(1-\phi)\left(\beta \sigma^{C}(1-\phi) \varepsilon \pi-2 \alpha \sigma^{I}\left(\sigma^{C}-\phi\right)(\varepsilon-\pi)\right)}}>0 .
$$

Figure 2 summarises. This is a centrally important result of our analysis: As skill-biased technological advance raises the productivity of high-skilled people while leaving the productivity of low-skilled people unchanged, the latter are increasingly are drawn to communitarianism while the former are drawn increasingly to individualism. In the process, the multi-affiliated group is hollowed out. ${ }^{13}$ The political consequences of this social fragmentation are documented by Han (2016): as income inequality rises, support for radical right-wing parties goes up among the poor but falls among the wealthy in European

\footnotetext{
${ }^{13}$ The result of Eq. 11 wherein the elite "pull away" is mirrored in the model of Collier (2019). Collier's model does not however predict the effect of increased communitarianism by the left-behind shown in Eq. 12 .
} 
countries.

It is important to recognize that two phenomena are responsible for these results. First, there is obviously the outcomes from the communitarian pursuits are clearly more egalitarian than the outcomes from the individualistic pursuits. This is the reason why skill-biased technological progress induces the relatively high-skilled multi-affiliated citizens to become individualists: they gain more in status from an individualistic identity than from a multi-affiliated one. Second, status-seeking pursuits generate negative consumption externalities (i.e. my rise in status comes at the expense of your fall in status) whereas communitarian pursuits do not. This the reason why the relatively low-skilled multi-affiliated citizens to become communitarians: they can avoid their loss of status (relative to higher-skilled citizens) by switching from a multi-affiliated to a communitarian identity. As a result, the society become more polarized, in the sense that there are fewer citizens who pursue both communitarian and individualistic pursuits (i.e. fewer multi-affiliates). As citizens stop sharing common objectives, the political process underlying economic policy making becomes more conflictual, as shown below.

\section{$5 \quad$ Policy Implications}

In the presence of widening socioeconomic inequality (skill-biased technological progress), it may be worthwhile for the underprivileged to favour economic policies that strengthen community solidarity, even if these policies make everyone materially worse off. The reason is that community solidarity is sufficiently important to the underprivileged to warrant the sacrifice in terms of foregone consumption and has the added advantage of lessening the positional consumption concerns of those with partially individualistic values. In this way our analysis accounts for the observation that nationalist communitarians tend to vote for protectionist economic policies, which impede productivity and thereby reduce everyone's purchasing power.

Specifically, we consider a policy - to be called "protectionism" - that uniformly reduces all agents' productivity $\beta_{j}$ by a factor of $1-\tau>0$, where $\tau$ represents that magnitude of the productivity-destruction effect:

$$
x_{i}=(1-\tau) \beta_{j}\left(1+a_{i}\right) \quad \forall i, j .
$$

We also assume that the policy raises the utility from communitarian activities:

$$
\frac{d \alpha}{d \tau}=\delta
$$

Under such a policy, the boundary of the individualistic group becomes:

$$
\widehat{a}^{I}=\frac{\varepsilon}{\varepsilon-\pi}-\sqrt{\frac{\varepsilon \pi}{(\varepsilon-\pi)^{2}}-\frac{2 \phi \alpha \sigma^{I}}{\beta \sigma^{C}(1-\tau)\left(\sigma^{I}-(1-\phi)\right)(\varepsilon-\pi)}}
$$


while that of the purely nationalist group becomes

$$
\widehat{a}^{C}=\frac{\varepsilon}{\varepsilon-\pi}-\sqrt{\frac{\varepsilon \pi}{(\varepsilon-\pi)^{2}}-\frac{2\left(\sigma^{C}-\phi\right) \alpha \sigma^{I}}{\beta \sigma^{C}(1-\tau)(1-\phi)(\varepsilon-\pi)}}
$$

Note that both $\widehat{a}^{I}$ and $\widehat{a}^{C}$ rise unambiguously with protectionism $\tau$.

In order to assess who has an interest in voting for this protectionist policy, we examine how multiaffiliated utility depends on the productivity-destroying policy:

$$
\frac{d U_{i}^{M}}{d \tau}=\frac{1}{2 \sigma^{I}}(1-\phi)\left(\beta_{s}\left(a_{i}^{2}(\varepsilon-\pi)+\left(1-2 a_{i}\right) \varepsilon\right)-a_{s}\left(2+a_{s}\right)\left(\beta_{s}-\beta_{u}\right) \pi\right)+\frac{\delta \phi}{\sigma^{C}}
$$

Note that the benefit of the policy to multi-affiliates falls with their ability (i.e. $d U_{i}^{M} / d \tau$ falls with $a_{i}$ ):

$$
\frac{d^{2} U_{i}^{m}}{d \tau d a_{i}}=-\frac{\beta_{s}}{\sigma^{I}}(1-\phi)\left(\left(1-a_{i}\right) \varepsilon+a_{i} \pi\right)<0
$$

Equations 16 and 17 imply that the multi-affiliated individual with ability $a_{i}=\widetilde{a}$ such that $d U_{i}^{M} / d \tau=0$ is indifferent between adopting the productivity-destroying policy and not, and that all $M$ agents with ability $a_{i}<\widetilde{a}$ strictly prefer adopting the policy.

It is worth observing from the above that there are two potential reasons why someone with a multiaffiliated identity would vote for this policy. Firstly, the policy increases the return to having a communitarian values (by $\phi \delta \tau / \sigma^{C}$, see the final term in Eq. 16). Secondly, it dampens the extent of materialistic status competition. The combination of these two policy effects is particularly potent in polarised electorates: it is no worse for the purely communitarian than a policy which increases only the returns to national identity, while it draws in strictly more multi-affiliated voters. Conversely it will be more popular than a policy which only compressed the distribution of income but did not raise the utility of sociocentric values because status concerns are unimportant to a large share $\widehat{a}^{C}$ of the electorate. ${ }^{14}$

Setting $d U_{i}^{M} / d \tau=0$ and solving for $a_{i}$ yields the size of the group $\widetilde{a}$ that votes for the productivitydestroying policy:

$$
\widetilde{a}=\frac{\varepsilon}{\varepsilon-\pi}-\sqrt{\frac{\varepsilon \pi}{(\varepsilon-\pi)^{2}}-\frac{2 \delta \phi \sigma^{I}}{\beta \sigma^{C}(1-\phi)(\varepsilon-\pi)}}
$$

meaning that agents with $a_{i}<\widetilde{a}$ will vote for protectionism and those with $a_{i}>\widetilde{a}$ will vote against it. Note that only those with the communitarian and multi-affiliated identities will vote for the growthreducing policy $\left(\widetilde{a}<\widehat{a}^{I}\right){ }^{15}$ Importantly, the size of the coalition voting for this policy grows when $\beta_{s}$

\footnotetext{
${ }^{14}$ One can alternately imagine an alliance of those at either extreme of the electorate which combines an agenda of communitarian nationalism with the amplification of individualistic status competition. One such example is the coalition which elected George Bush president of the United States in 2004.

${ }^{15}$ Note that $\widehat{a}^{I}-\widetilde{a}=\sqrt{\frac{\varepsilon \pi}{(\varepsilon-\pi)^{2}}-\frac{2 \delta \phi \sigma^{I}}{\beta \sigma^{C}(1-\tau)(1-\phi)(\varepsilon-\pi)}}-\sqrt{\frac{\varepsilon \pi}{(\varepsilon-\pi)^{2}}-\frac{2 \phi \alpha \sigma^{I}}{\beta \sigma^{C}(1-\tau)\left(\sigma^{I}-(1-\phi)\right)(\varepsilon-\pi)}}>0$ so long as $\alpha>$ $\delta\left(\sigma^{I}-(1-\phi)\right) /(1-\phi)$ (i.e. the policy is sufficiently inefficient).
} 
goes up holding $\beta_{u}$ constant:

$$
\left.\frac{d \widetilde{a}}{d \beta_{s}}\right|_{\beta_{s}=\beta_{u}=\beta}=\frac{2 \delta \phi \sigma^{I}+a_{s}\left(2+a_{s}\right)(1-\phi) \beta \pi \sigma^{C}}{2 \beta \sqrt{\beta \sigma^{C}(1-\phi)\left(\beta \sigma^{C} \varepsilon(1-\phi) \pi-2 \delta \phi \sigma^{I}(\varepsilon-\pi)\right)}}>0 .
$$

In short, skill-biased technological change leads to social fragmentation (polarisation of values) and thereby increases the number of people favouring protectionism. As the supporters of protectionism become more and more numerous, it becomes more likely that a democratically elected government will pursue protectionist policies, even though these policies reduce productivity. Policies that make everyone materially worse off - like the protectionist policy above, which destroys a proportion of everyone's productivity - are chosen by communitarians and multi-affiliates for a simple reason. Their material standard of living is not the only source of their wellbeing. Rather, they also derive wellbeing from social pursuits and these pursuits are impeded by skill-biased technological change.

In focusing exclusively on wellbeing arising from material goods and services, conventional economic theory overlooks this rationale for protectionism. By extending our analysis to include both individualistic market activities and communitarian non-market activities, it becomes possible to recognize two effects of skill-biased technological change: (i) a rise in individualistic returns, generated by a rise in material living standards and (ii) a rise in social fragmentation, associated with lower communitarian returns and lower status for the low-ability individuals. The attractiveness of protectionism for the disadvantaged segment of the population lies in its promotion of communitarian goals, even if that comes at the expense of a reduced material living standard. Furthermore, the productivity-destroying policy acts to prevent some social fragmentation by making fewer citizens adopt a materialistic/individualistic identity, ${ }^{16}$ though more also adopt a purely communitarian identity. ${ }^{17}$

Naturally, our model not meant to be interpreted as an argument for protectionism, at least in the presence of skill-biased technological change. Instead, the extended purview of our analysis points to the need for innovation, education and training policies that reduce the skill bias of technological change. This can be done either by improving the skills of the least advantaged people, enabling them better to take advantage of technological advances, or by shaping the nature of technological change itself, through subsidizing innovations that improve the lot of the disadvantaged.

\footnotetext{
${ }^{16}$ This may be seen by

$$
d \widehat{a}^{I} / d \tau=\frac{\phi \sigma^{I}(\delta+\alpha)}{(1-\tau)^{3 / 2} \sqrt{\beta \sigma^{C}\left(\sigma^{I}-(1-\phi)\right)\left(\beta \varepsilon \pi \sigma^{C}(1-\tau)\left(\sigma^{I}-(1-\phi)\right)-2 \phi \alpha \sigma^{I}(\varepsilon-\pi)\right)}}>0 .
$$

${ }^{17}$ Similarly

$$
d \widehat{a}^{C} / d \tau=\frac{\sigma^{I}\left(\sigma^{C}-\phi\right)(\delta+\alpha)}{(1-\tau)^{3 / 2} \sqrt{\beta \sigma^{C}(1-\phi)\left(\beta \varepsilon \pi \sigma^{C}(1-\phi)(1-\tau)-2 \alpha \sigma^{I}\left(\sigma^{C}-\phi\right)(\varepsilon-\pi)\right)}}>0 .
$$
}




\section{Concluding Remarks}

While conventional economic theory rests on consumption-oriented utilitarian values, these are not the only values that people cherish. Our analysis has focused on one important additional value: loyalty to one's tribe. In the latter, consumption flowing to oneself is not essential. Instead, sources of group esteem are important, such as displays of national or religious power, even if they reduce material wealth (as is frequently the case under trade war or military conflict).

Our model highlights a new channel whereby economic inequality hampers economic growth. Rising inequality leads to rising social fragmentation, measured by the increasing polarisation of values. The elite progressively abandon communitarian goals and focus increasingly on individualistic material goals. These developments leave the underprivileged worse off in two respects: first, they fall progressively behind in the competition for positional goods and, second, their public goods associated with social allegiances fall, due to the exodus of the privileged from community pursuits. On this account, the elite's rising preoccupation with individualistic material goals is matched by a rising preoccupation of the underprivileged with communitarian goals.

Moral fragmentation deserves attention in economic analysis since, as our model indicates, it can have both economic sources (e.g. globalisation and innovation) and economic consequences (e.g. protectionism). The ideological divides associated with the moral divides are also apparent in the rebirth of strident nationalist and fascist political movements in many countries around the world. Furthermore, the moral divides are evident in the political conflicts concerning gender issues and religious fundamentalism, each of which have important economic consequences. Our analysis also indicates that this moral fragmentation is potentially important for understanding a variety of economic problems, including inequalities, the political economy of populism, and the decline of the welfare state. Finally, the conflict between rival identities associated with this moral fragmentation has had profound implications for public policy and governance - including the underclass's mistrust of the governing elites; the elites' paternalism and their falling willingness to support welfare services for the poor; and the declining willingness of citizens to contribute voluntarily to public goods and common pool resources. 


\section{References}

[1] Akerlof, G. A. \& Kranton, R. E. (2000). Economics and Identity. Quarterly Journal of Economics, 115(3), 715-753.

[2] Akerlof, R. (2017). Value formation: The role of esteem. Games and Economic Behavior, 102, 1-19.

[3] Arnorsson, A. \& Zoega, G. (2018). On the causes of Brexit. European Journal of Political Economy, $55,301-323$.

[4] Baldwin, R. (2016). The Great Convergence: Information technology and the new Globalization. Cambridge, MA: Harvard University Press.

[5] Bennet, W.J. (1993). The Book of Virtues: A Treasury of Great Moral Stories. New York: Simon and Schuster.

[6] Boyce, C. J., Brown, G. D. A., \& Moore, S. C. (2010). Money and happiness: Rank of income, not income, affects life satisfaction. Psychological Science, 21(4), 471-475.

[7] Carvalho, J,-P. \& Koyama, M. (2016). Jewish emancipation and schism: Economic development and religious change. Journal of Comparative Economics, 44(3), 562-584.

[8] Chappell, T.D.J. (2006). Values and Virtues: Aristotelianism in Contemporary Ethics. Oxford: Oxford University Press.

[9] Collier, P. (2018). The Future of Capitalism. London: Penguin.

[10] Collier, P. (2019). Diverging identitities: A model of class formation. Social Macroeconomics Working Paper Series, SM-WP-2019.

[11] Crisp, R. (1996). How Should One Live? Essays on Virtues. Oxford: Oxford University Press.

[12] Fetzer, T. (2018). Did austerity cause Brexit? Warwick economics research papers series (WERPS), 1170.

[13] Gilligan, C. (1982). In a Different Voice: Psychological theory and women's development. Cambridge, MA: Harvard University Press.

[14] Haidt, J. (2012). The Righteous Mind. London: Allen Lane.

[15] Han, K. J. (2016). Income inequality and voting for radical right-wing parties. Electoral Studies, 42, $54-64$.

[16] Hudders, L. \& Pandelaere, M. (2012). The silver lining of materialism: The impact of luxury consumption on subjective well-being. Journal of Happiness Studies, 13(3), 411-437.

[17] Hunter, J. D. (1991). Culture Wars: The Struggle to Define America. New York: Basic Books.

[18] Inglehart, R. (1977). The Silent Revolution. Princeton: Princeton University Press.

[19] Inglehart, R. (1990). Cultural Shift in Advanced Industrial Society. Princeton: Princeton University Press.

[20] Inglehart, R. (1997). Modernization and Postmodernization: Cultural, economic and political change in 43 Societies. Princeton: Princeton University Press.

[21] Inglehart, R. \& Welzel, C. (2005). Modernization, Cultural Change and Democracy: The human development sequence. New York: Cambridge University Press.

[22] Kesebir, S. \& Haidt, J. (2010). Morality. In: Handbook of Social Psychology, S. Fiske, D. Gilbert, \& G. Lindzey (Eds.), 5th ed., pp. 797-832. Hoboken, NJ: Wiley.

[23] Kohlberg, L. (1969). Stage and sequence: The cognitive-developmental approach to socialization. In: Handbook of Socialization Theory and Research, D. A. Goslin (Ed.). Chicago: Rand McNally.

[24] MacIntyre, A. (1981). After Virtue. Notre Dame: University of Notre Dame Press. 
[25] Markus, H. R. \& Kitayama, J. d. S. (1991). Culture and the Self: Implications for cognition, emotion and motivation. Psychological Review, 98, 224-53.

[26] Pieters, R. (2013). Bidirectional dynamics of materialism and loneliness: Not just a vicious cycle. Journal of Consumer Research, 4(1), 615-631.

[27] Rawls, J. (1971). A Theory of Justice. Cambridge, MA: Harvard University Press.

[28] Roberts, J. A. \& Clement, A. (2007). Materialism and satisfaction with over-all quality of life and eight life domains. Social Indicators Research, 82(1), 79-92.

[29] Rodrik, D. (2014). When ideas trump interests: Preferences, worldviews, and policy innovations. Journal of Economic Perspectives, 28(1), 189-208.

[30] Rothwell, J. (2016). Economic hardship and favorable views of Trump. Gallup, July 22.

[31] Ryan, L. \& Dziurawiec, S. (2001). Materialism and its relationship to life satisfaction. Social Indicators Research, 55(2), 185-197.

[32] Shweder, R. A. \& Borne, E. (1984). Does the concept of the Person vary cross-culturally? In: Cultural Theory, R. Shweder \& R. LeVine (Eds.), pp. 158-199. Cambridge, UK: Cambridge University Press.

[33] Schwartz, S. H. (1994). Are there universal aspects in the structure and contents of Human values? Journal of Social Issues, 50(4), 19-45.

[34] Silver, N. (2016a). The mythology of Trump's 'working class' support: His voters are better off economically compared with most Americans. FiveThirtyEight, May 3.

[35] Silver, N. (2016b). Education, not income, predicted who would vote for Trump. FiveThirtyEight, Nov. 22.

[36] Snower, D. J. \& Bosworth, S. J. (2016). Identity-driven cooperation versus competition. American Economic Review: Papers and Proceedings, 106(5), 420-424.

[37] Tönnies, F. (1887/2001). Community and Civil Society, J. Harris \& M. Hollis (trans.). Cambridge, UK: Cambridge University Press.

[38] Triandis, H. C. (1995). Individualism and Collectivism. Boulder, CO: Westview Press.

[39] Van Lange, P. A. M., Otten, W., De Bruin, E. M. N., \& Joireman, J. A. (1997). Development of prosocial, individualistic, and Competitive orientations: Theory and preliminary evidence. Journal of Personality and Social Psychology, 73, 733-746. 


\section{Appendix}

We now relax the assumption from Section 4 that the baseline technology is skill-unbiased $\left(\beta_{u}=\beta_{s}=\beta\right)$ with the assumption that the baseline technology may be skill-biased. Here are expressed the general cases of the important equations with this assumption relaxed. Firstly, the boundary between the multiaffiliated identity group and the individualistic identity group, defined by the marginal individual $\widehat{a}^{I}$ as expressed in Equation 9:

$$
\widehat{a}^{I}=\frac{\varepsilon}{\varepsilon-\pi}-\sqrt{\frac{\varepsilon \pi}{(\varepsilon-\pi)^{2}}+\frac{a_{s}\left(2+a_{s}\right)\left(\beta_{s}-\beta_{u}\right) \pi}{\beta_{s}(\varepsilon-\pi)}-\frac{2 \phi \alpha \sigma^{I}}{\beta_{s} \sigma^{C}\left(\sigma^{I}-(1-\phi)\right)(\varepsilon-\pi)}} .
$$

We can similarly show the boundary between the multi-affiliated identity group and the communitarian identity group (and correspondingly the size of the communitarian group), defined by the marginal individual $\widehat{a}^{C}$ as expressed in Equation 10:

$$
\widehat{a}^{C}=\frac{\varepsilon}{\varepsilon-\pi}-\sqrt{\frac{\varepsilon \pi}{(\varepsilon-\pi)^{2}}-\frac{\left(1+a_{s}\right)\left(3+a_{s}\right)\left(\beta_{s}-\beta_{u}\right) \varepsilon}{\beta_{u}(\varepsilon-\pi)}-\frac{2 \sigma^{I}\left(\sigma^{C}-\phi\right) \alpha}{\beta_{u} \sigma^{C}(1-\phi)(\varepsilon-\pi)}} .
$$

Next, we show how the marginal individual $\widehat{a}^{I}$ is now less skilled when skill-biased income growth occurs, represented by an increase in $\beta_{s}$ holding $\beta_{u}$ constant, as seen in Equation 11:

$$
\begin{aligned}
\frac{d \widehat{a}^{I}}{d \beta_{s}} & =-\frac{\left(\sigma^{I}-(1-\phi)\right)\left(2+a_{s}\right) a_{s} \beta_{u} \pi \sigma^{C}+2 \phi \alpha \sigma^{I}}{2 \beta_{s} \sqrt{\beta_{s} \sigma^{C}\left(\sigma^{I}-(1-\phi)\right)\left(\left(\sigma^{I}-(1-\phi)\right)\left(\beta_{s} \varepsilon \pi \sigma^{C}+(\varepsilon-\pi) \pi a_{s}\left(2+a_{s}\right)\left(\beta_{s}-\beta_{u}\right)\right)-2 \alpha \phi \sigma^{I}(\varepsilon-\pi)\right)}} \\
& <0 .
\end{aligned}
$$

This means that more of the skilled population "pulls away" from communitarian values. Likewise, the marginal individual $\widehat{a}^{C}$ is now more skilled when skill-biased income growth occurs, as seen in Equation 12:

$$
\begin{aligned}
\frac{d \widehat{a}^{C}}{d \beta_{s}} & =\frac{\left(1-a_{s}\right)\left(3+a_{s}\right)(1-\phi) \sigma^{C} \varepsilon}{2 \sqrt{\beta_{u} \sigma^{C}(1-\phi)\left(\beta_{u} \sigma^{C}(1-\phi) \varepsilon \pi-(\varepsilon-\pi) \varepsilon\left(1-a_{s}\right)\left(3+a_{s}\right)(1-\phi)\left(\beta_{s}-\beta_{u}\right)-2 \alpha \sigma^{I}\left(\sigma^{C}-\phi\right)(\varepsilon-\pi)\right)}} \\
& >0
\end{aligned}
$$

i.e. more of the upper end of the unskilled population gravitates towards pure communitarianism as they are "left behind". The consequences for political economy are seen in the change in the marginal voter $\widetilde{a}$, who is just indifferent to adopting the productivity-destroying policy, given by Equation 18:

$$
\widetilde{a}=\frac{\varepsilon}{\varepsilon-\pi}-\sqrt{\frac{\varepsilon \pi}{(\varepsilon-\pi)^{2}}-\frac{a_{s}\left(2+a_{s}\right)\left(\beta_{s}-\beta_{u}\right) \pi}{\beta_{s}(\varepsilon-\pi)}-\frac{2 \delta \phi \sigma^{I}}{\beta_{s} \sigma^{C}(1-\phi)(\varepsilon-\pi)}} .
$$


Since all with ability $a_{i}<\widetilde{a}$ are predicted to vote for this policy, we can see how the size of the political constituency for productivity-destroying policies grows with skill-biased technological change from Equation 19:

$$
\frac{d \widetilde{a}}{d \beta_{s}}=\frac{2 \delta \phi \sigma^{I}+a_{s}\left(2+a_{s}\right)(1-\phi) \beta_{u} \pi \sigma^{C}}{2 \beta_{s} \sqrt{\beta_{s} \sigma^{C}(1-\phi)\left((1-\phi) \pi\left(\beta_{s} \sigma^{C} \varepsilon+a_{s}\left(2+a_{s}\right)\left(\beta_{s}-\beta_{u}\right)(\varepsilon-\pi)\right)-2 \delta \phi \sigma^{I}(\varepsilon-\pi)\right)}}>0 .
$$

